Original Research Article

\title{
Comparative study of wound healing effect of topical Acacia catechu extract and silver sulfadiazine on excisional wound model in guinea pigs
}

\author{
Sunitha Tangeti ${ }^{1}$, Padmaja Gabbita ${ }^{2 *}$, Raghunatha R. Ponnaluri ${ }^{2}$, Bhanu P. Kolasani ${ }^{3}$
}

\begin{abstract}
${ }^{1}$ Department of Pharmacology, Government Medical College, Siddipet, Telangana, India ${ }^{2}$ Department of Pharmacology, Gandhi Medical College, Secunderabad, Telangana, India ${ }^{3}$ Department of Pharmacology, Vinayaka Missions Medical College, Vinayaka Missions Research Foundation (Deemed to be University), Salem, Tamil Nadu, India
\end{abstract}

Received: 01 November 2018 Accepted: 12 November 2018

\section{*Correspondence to: \\ Dr. Padmaja Gabbita, Email: padmajasreenu@ gmail.com}

Copyright: (C) the author(s), publisher and licensee Medip Academy. This is an openaccess article distributed under the terms of the Creative Commons Attribution NonCommercial License, which permits unrestricted noncommercial use, distribution, and reproduction in any medium, provided the original work is properly cited.

\begin{abstract}
Background: Impaired and aberrant wound healing imposes a huge financial burden and places an enormous drain in health care resources in the developed world and an insurmountable problem in the developing countries too. In this study, authors have compared the wound healing effect of topical application of Acacia catechu extract with silver sulfadiazine in excisional wound model in guinea pigs.
\end{abstract}

Methods: Twelve guinea pigs were randomly divided into two groups $(n=6)$. The wound healing was observed in excision model. The standard group is treated with silver sulfadiazine (group 1) and the test group with Acacia catechu extract (group 2). The mean wound size expressed in $\mathrm{mm}^{2}$ and the mean percentage of the wound healed was measured on day $0,4,8,12,16$ and 19. Biopsy was done on day 21 for histopathological examination (HPE).

Results: Statistical analysis was done by using unpaired t test for between the groups comparison and by using paired t test for within the group comparison. The mean percentage of the wound healed with-in the groups was found to be statistically highly significant ( $p$ value $<0.001$ ) and in between the groups was found to be statistically non-significant ( $p$ value $>0.05$ ). A comparable increase in collagen content and granulation tissue was found on HPE in both the groups on day 21 .

Conclusions: Wound healing effect of the Acacia catechu extract is equal to and comparable with that of silver sulfadiazine.

Keywords: Acacia catechu extract, Excisional wound model, Silver sulfadiazine, Wound healing

\section{INTRODUCTION}

Wound is defined as the disruption of cellular and anatomical continuity of tissue integrity and sometimes associated with loss of function. Restoration of damaged tissue plays a vital role in survival of life and it is imminent for basis of all surgical manipulations. Healing occurs after practically any insult that causes tissue destruction and is essential for survival of the organism. ${ }^{1}$

\begin{abstract}
The aim of wound care is to promote wound healing in the shortest time possible, with minimal pain, discomfort, and scarring to the patient and must occur in a physiologic environment conducive to tissue repair and regeneration. ${ }^{2}$ Multiple local disturbances like infection, hypoxia, trauma, foreign bodies, extrinsic factors like mechanical stress, debris, temperature, infection, chemicals,
\end{abstract}


medications, alcohol abuse, smoking and systemic diseases such as diabetes mellitus and malnutrition can result in impaired wound healing. Impaired and aberrant wound healing imposes a huge financial burden and places an enormous drain in health care resources in the developed world and an insurmountable problem in the developing countries too.

The prevalence of the chronic wounds in the community was reported as 4.5 per 1000 population, where as that of acute wounds was nearly double, at 10.5 per 1000 population. ${ }^{3}$ In the course of lifetime $10 \%$ of population will develop a chronic wound related morbidity and mortality rate of $2.5 \%$. Every 30 seconds a lower limb is lost somewhere in the world as a consequence of DM. ${ }^{4}$ Today in developing countries up to $80 \%$ of the population depend mainly on medicinal plants for their health care. It has been estimated that $1 / 3$ of all traditional herbal medicines are used for the treatment of wounds and skin disorders. ${ }^{5}$

With development of new scientific methods, there is an increasing interest in worldwide in search of bioactive ingredients from herbal plants. Some of the plants possess pro-wound healing activities and exhibit antimicrobial, astringent, anti-inflammatory, antioxidant and other related properties which are beneficial in various stages of wound healing process. WHO has emphasized the need for better utilization of medicinal plants widely in facilitating wound healing with high degree of success in countries like China and India.

One of the plants traditionally used for treatment of wounds is Acacia catechu belonging to the family Mimosaceae. The bark of the plant is made into a paste and applied over the wounds for faster healing which can be a cost-effective treatment of wound healing. ${ }^{6}$ In previous studies evaluations were done with $2 \%, 4 \%$ ointment as topical applications once daily. ${ }^{7}$ In previous studies the wound healing property was compared between alcoholic and ethnolic Acacia catechu extracts, with the standard, soframycin, nitrofuracin, in rats. ${ }^{8}$

In this study, authors have compared the wound healing effect of topical application of Acacia catechu extract with silver sulfadiazine in excisional wound model in guinea pigs.

\section{METHODS}

The study was undertaken to evaluate the wound healing effect of Acacia catechu extract in comparison with Silver sulfadiazine in guinea pigs, in the Department of Pharmacology, Gandhi Medical College, Secunderabad, after obtaining prior approval from Institutional Animal Ethics Committee, GMC. Experimental work and formulations were carried out under sterile conditions.

Healthy guinea pigs of both sexes of 3-4 months old, weighing 450- 550gms were procured from Central animal house (Reg.no: 428/01C/CPCSEA), Department of Pharmacology, GMC, Secunderabad. The guinea pigs were randomly selected for both the groups after 7 days of acclimatization period (Table 1). They were housed in appropriately labelled steel cages according to groups in a room maintained at $12 \mathrm{hr}$ light-dark cycles and at a constant temperature of $24 \pm 2^{\circ} \mathrm{C}$. The guinea pigs were provided with food consists of lucine grass, bengal gram and water ad-libitum.

The excisional wound model was chosen to study, as the healing process is by secondary intention. ${ }^{9}$ If tissue injury is severe or chronic, resulting in damage of both parenchymal and stromal frame work of the tissue, healing cannot be accomplished by regeneration. Repair by deposition of collagen and other extracellular matrix, causing the formation of a scar is inevitable. Hence the excisional biopsy if taken from edge of the wound to confirm the increase in collagen content.

\section{Excisional wound model ${ }^{9}$}

The guinea pigs were anaesthetized by intraperitoneal injection of ketamine $50 \mathrm{mg} / \mathrm{kg}$. Under local infiltration of $1 \%$ xylocaine $5 \mathrm{mg} / \mathrm{kg}$, the animals were shaved on the back and the skin was disinfected using cotton. The anticipated area of the wound to be created was outlined on the back of the animals with methylene blue. A rectangular full thickness excision wound of area $500 \mathrm{~mm}^{2}$ and a depth of $2 \mathrm{~mm}$ was created along the markings, using sterile toothed forceps, scalpel and pointed scissors, in the para vertebral area, $2 \mathrm{~cm}$ from midline, over the back (Figure 1). The same procedure was performed for all the guinea pigs. The drugs were applied topically, twice daily till the complete epithelialisation, starting from the day of operation. To measure the area of the wounds, a transparent plastic paper was placed on the location of the wound and its shape was drawn on the same paper with a marker. These wound tracings were retraced on a millimeter scale graph paper to determine the wound area, expressed as in $\mathrm{mm}^{2}$. The wounds were measured in the same position, at regular intervals. The wounds were traced on graph paper on day 4, 8, 12, 16 and day 19 of the experiment.

Percentage of wound healing was calculated according to the Walker formula. ${ }^{10}$

Percentage of wound area $=\frac{\text { wound area on day } \mathrm{x}}{\text { wound area on day } 0} \times 100$

Percentage of wound healing $=100-$ percentage of wound area.

The total number of days required for complete epithelialisation of the wound was noted in each guinea pig in both the groups. On $21^{\text {st }}$ day the excision biopsy was taken, including the adjacent normal skin and sent for HPE, to confirm the increase in collagen tissue and granulation tissue. 


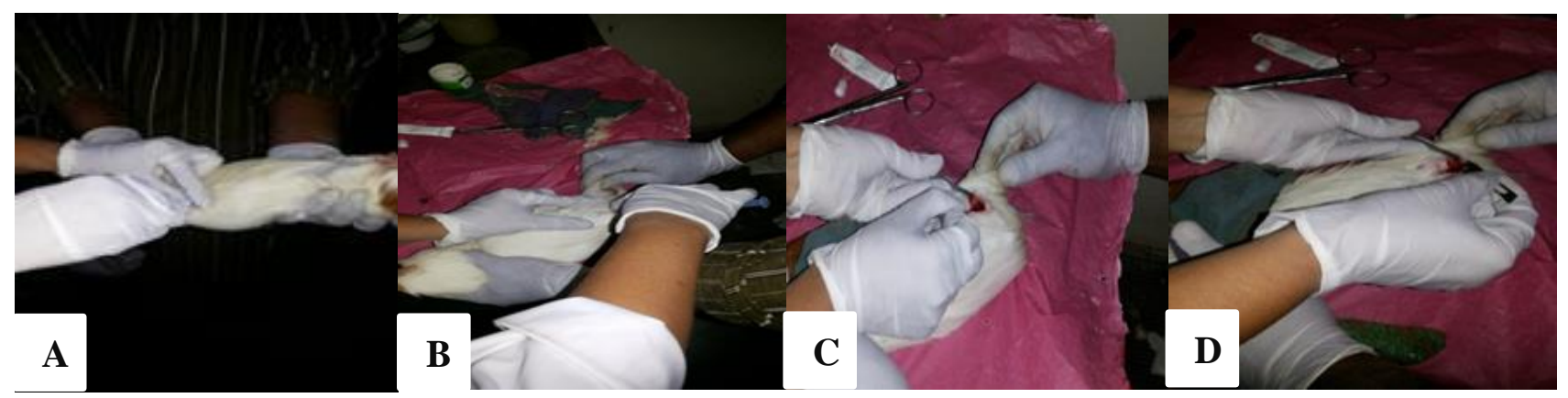

Figure 1: Procedure of inducing excision wound model in guinea pigs. (A): guinea pigs being anaesthetized by intraperitoneal injection of ketamine $50 \mathrm{mg} / \mathrm{kg}$, (B): local infiltration of $1 \%$ xylocaine $5 \mathrm{mg} / \mathrm{kg}$, (C): creating rectangular full thickness excision wound using sterile toothed forceps, (D): scalpel and pointed scissors in the para vertebral area of guinea pigs.

\section{RESULTS}

All values are expressed as mean \pm SEM. Statistical difference in mean was analysed by using unpaired t test in between the groups and by using paired t test in within the group. $\mathrm{P}$ value less than 0.05 was considered as statistically significant.

Table 1: Allotment of guinea pigs in to control group and test group.

\begin{tabular}{|lll|}
\hline & Drug & No. of guinea pigs \\
\hline Group 1 & $\begin{array}{l}\text { Silver sulfadiazine } \\
\text { (control) }\end{array}$ & 06 \\
\hline Group 2 & $\begin{array}{l}\text { Acacia catechu } \\
\text { extract (test) }\end{array}$ & 06 \\
\hline
\end{tabular}

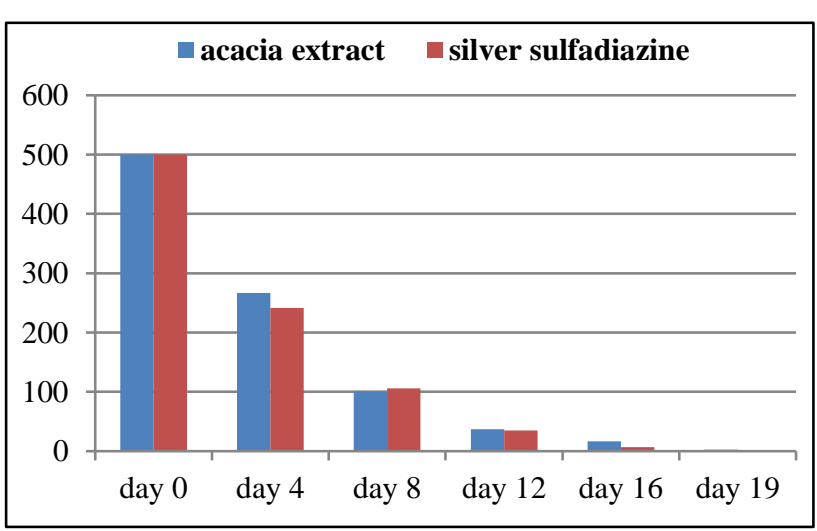

Figure 2: Mean wound size measured in $\mathrm{mm}^{2}$ on various days.

The mean percentage of the wound healed in group 1 (silver sulfadiazine) was found to be $53.3 \%$ on day 4 , $78.3 \%$ on day $8,93 \%$ on day $12,98.6 \%$ on day 16 and $99 \%$, on day 19 whereas the mean percentage of wound healed in group 2 (Acacia catechu extract) was found to be 46.6 $\%$ on day $4,79.2 \%$ on day $8,92.7 \%$ on day $12,96.65$ on day 16 and $99.5 \%$ on day 19 (Table 3 and Figure 3). This indicates that almost half of the wound was healed by day 4 in both the groups. Even on the other days, the percentage of wound healing was quite comparable in both the groups.

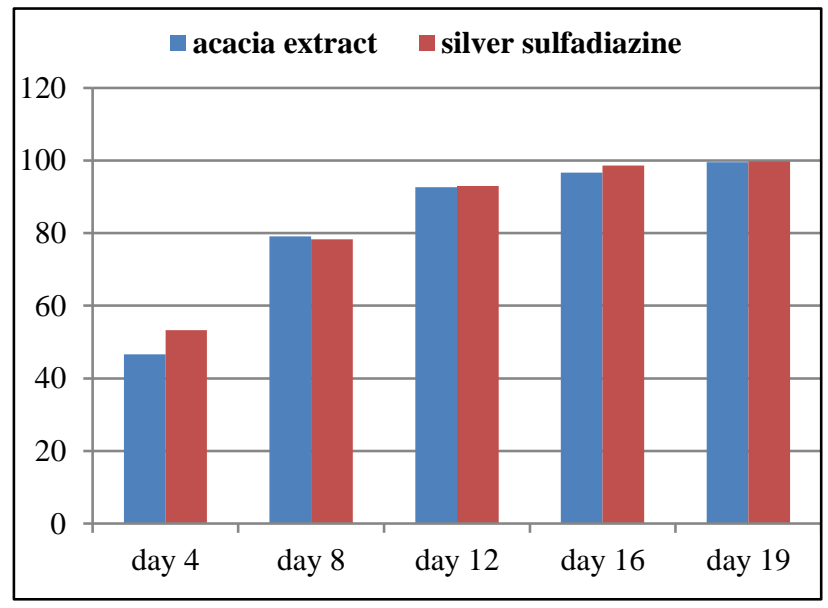

Figure 3: Mean values of percentage of wound healed on various days.

The mean wound size on day 0 (day on which excisional wound was induced) was $500 \mathrm{~mm}^{2}$ which was taken as a baseline measure with which the mean sizes of the wound on various days will be compared.

The mean wound sizes measured by taking transparent plastic paper retraced on graph paper in group 1 (silver sulfadiazine) were found to be $241.16 \mathrm{~mm}^{2}$ on fourth day, $105.83 \mathrm{~mm}^{2}$ on eighth day, $35.00 \mathrm{~mm}^{2}$ on twelfth day, 6.67 on sixteenth day and 0.57 on nineteenth day. The mean wound sizes in group 2 (Acacia catechu extract) were found to be $266.67 \mathrm{~mm}^{2}$ on day $4,100.66 \mathrm{~mm}^{2}$ on day 8 , $36.66 \mathrm{~mm}^{2}$ on day $12,16.67 \mathrm{~mm}^{2}$ on day 16 and $2.5 \mathrm{~mm}^{2}$ on day 19 (Table 2 and Figure 2).

In present study, the number of days required for falling of the scar without any residual raw surface, which is called as the period of epithelialisation, was found to be around 16 - 20days. 
The mean values of the percentage of the wound healed was found to be highly significant ( $p$ value $<0.001$ ) when compared 'with in' the groups but the mean percentage of the wounds healed between the two groups on similar days were found to be not statistically significant ( $\mathrm{p}$ value $>0.05$ ) (Table 3).
The results of the biopsy which was done for histopathological examination on day 21 reflected a similar increase in collagen content and granulation tissue in the both the groups which proves that histologically also the wound healing in both the groups was very good and comparable (Figures 4 and 5).

Table 2: Mean wound size measured in $\mathrm{mm}^{2}$ on various days.

\begin{tabular}{|lllllll|}
\hline & Day 0 & Day 4 & Day 8 & Day 12 & Day 16 & Day 19 \\
\hline Group 1 & 500 & 241.16 & 105.83 & 35.0 & 6.67 & 0.5 \\
\hline Group 2 & 500 & 266.67 & 100.66 & 36.66 & 16.67 & 2.5 \\
\hline
\end{tabular}

Table 3: Mean values of percentage of wound healed on various days.

\begin{tabular}{|lllllll|}
\hline & Day 4 & Day 8 & Day 12 & Day 16 & Day 19 & P value \\
\hline Group 1 & 53.33 & 78.33 & 93 & 98.66 & 99.75 & $0.0001 * *$ \\
\hline Group 2 & 46.6 & 79.16 & 92.66 & 96.66 & 99.5 & $0.0001 * *$ \\
\hline P value & $0.32 *$ & $0.62 *$ & $0.87 *$ & $0.08 *$ & $0.10 *$ & \\
\hline
\end{tabular}

$* \mathrm{P}$ value not statistically significant; $* * \mathrm{P}$ value statistically highly significant

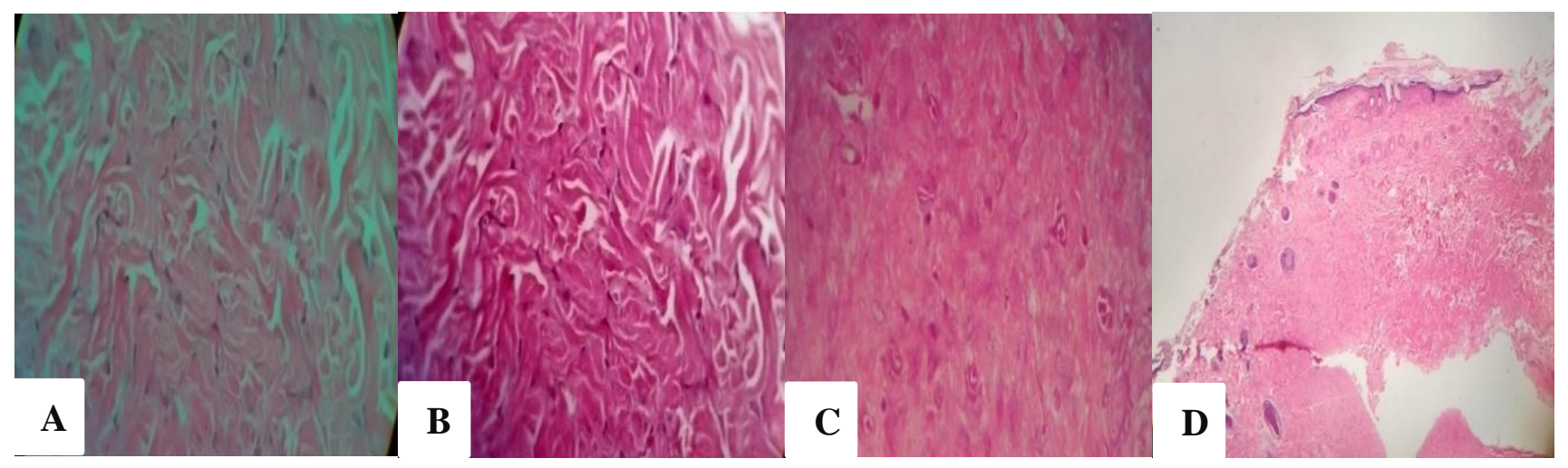

Figure 4: Histopathological examination for increase in collagen and granulation tissue in group 1 (silver sulfadiazine). (A): collagen tissue in normal wound (without any drug), (B): collagen tissue in wound with topical silver sulfadiazine application, (C): granulation tissue in normal wound (without any drug), (D): collagen tissue in wound with topical silver sulfadiazine application.

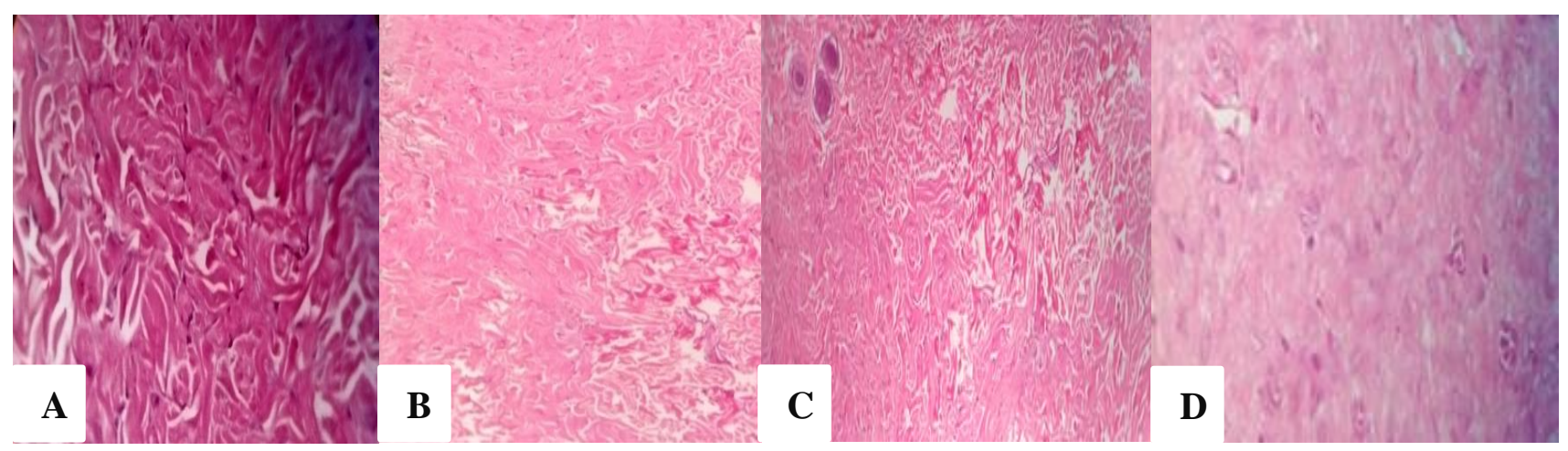

Figure 5: Histopathological examination for increase in collagen and granulation tissue in group 2 (Acacia catechu extract). (A): collagen tissue in normal wound (without any drug), (B): collagen tissue in wound with topical Acacia catechu extract application, (C): granulation tissue in normal wound (without any drug), (D): collagen tissue in wound with topical Acacia catechu extract application. 


\section{DISCUSSION}

The collective response of skin to injury is termed as wound healing. At times both regeneration and repair, may take place simultaneously. Wound contraction is the process, generally occurs in large surface wounds. The balance between ECM synthesis and degradation results in remodelling of the connective tissue framework - an important feature of tissue repair. The breaking strength or the tensile strength of granulation tissue increases proportionately with fibrillar collagen deposition, the major protein of the intracellular matrix. The collagen is composed of hydroxyproline, a biochemical marker of collagen turnover is done to know the strength of wound healing.

Acacia catechu was widely used in Ayurveda to treat various diseases and mainly ulcers boils and eruptions of the skin, leprosy and wound healing effectively. ${ }^{11}$ In East Africa, the powdered bark of this tree was applied to treat cancerous growths. ${ }^{12}$ Acacia catechu is biologically very active and reflected the significant promotion and potentiation of wound healing activity in the natural and safer way. ${ }^{13}$ Traditional knowledge needs scientific validation, standardization to discover intentional, focussed and safe natural product drug. The need is to do more research to identify active constituents which are responsible for its biological activity. ${ }^{14}$

The present study was based on the wound healing efficacy of Acacia catechu extract in comparison with the standard drug silver sulfadiazine in excisional model. The parameters studied were wound contraction, percentage wound healing (epithelialisation) on day $0,4,8,12,16$ and 19 and histopathological examination for collagen content and granulation tissue by taking biopsy on day 21 .

On statistical analysis of the parameters, the mean percentage of the wound healed was found to be statistically highly significant within the group when compared between day 0 and day 19 ( $\mathrm{p}$ value $<0.001$ ) and in between the groups it was found to be statistically nonsignificant ( $\mathrm{p}$ value $>0.05$ ). Biopsy on day 21 reflected a comparable increase in collagen content and granulation tissue in HPE of both the groups. In this study, we observed that the wound healing effect of the Acacia catechu extract was comparable to that of silver sulfadiazine

In the present study, complete epithelialisation was observed to be around 16-20 days and similar results were observed in the previous studies. ${ }^{15,16}$ In a similar study wound healing potential of the aqueous and alcoholic extracts of Acacia catech $u$ bark in the form of an ointment with two different concentrations ( $2 \%$ and $4 \% \mathrm{w} / \mathrm{w}$ ) was evaluated in comparison with Framycetin in excision wound models in ratsin which the aqueous extract of Acacia catechu at $4 \% \mathrm{w} / \mathrm{w}$ showed significant wound healing activity $(\mathrm{P}<0.001) \cdot{ }^{17} \mathrm{In}$ a similar study, there was significant increase in percentage wound contraction and decrease in period of epithelialisation in excision wound model in rats. ${ }^{18}$

The wound healing property of Acacia catechu may be attributed to the phytoconstituents such as tannins, saponins, alkaloids and flavonoids. ${ }^{19}$ Tannins are known to promote the wound- healing process mainly due to their astringent and antimicrobial property. ${ }^{20}$ Constituents like saponins and alkaloids may play a role in tissue regeneration in the process of wound healing..$^{21,22}$ In addition to providing the nutrition to the healing tissues, the Acacia catechu extract was shown the beneficiary effect on each and every stage of the wound healing, including the inflammatory, fibroplasia, remodelling phases of the ordinary wounds and as well as the chronic wounds. ${ }^{23,24}$

The onset of cell necrosis is reduced by flavonoids because of its reduction in lipid peroxidation and by improved vascularity, increasing the viability of collagen fibrils by increasing the strength of collagen fibers, preventing the cell damage, promoting the DNA synthesis. ${ }^{25-27}$

Further studies with large number of animals and largescale clinical studies are needed to finally acertain the true value of this plant compound which is having multiple effects.

\section{ACKNOWLEDGEMENTS}

Authors would like thanks to all the staff of Department of Pharmacology for their constant support throughout the study without which this study would not be possible.

Funding: No funding sources

Conflict of interest: None declared

Ethical approval: The study was approved by the Institutional Ethics Committee

\section{REFERENCES}

1. Nayak BS, Anderson M, Pereira LP. Evaluation of wound-healing potential of Catharanthus roseus leaf extract in rats. Fitoterapia. 2007 Dec 1;78(7-8):540-4.

2. Bowler PG, Duerden BI, Armstrong DG. Wound microbiology and associated approaches to wound management. Clin Microbiol Reviews. 2001 Apr 1;14(2):244-69.

3. Shukla K, Ansari MA. An Indian community based epidemiological study of wounds. J Wound Care. 2004;(13):323-5.

4. Sasank CS. Venous ulcer of lower limb, where do we stand? Indian J Plastic Surgery. 2012; 45(2):266-274.

5. Valte V, Singh TI, Singh OJ, Babycha L, Aruna S. Protective effect of ethyl acetate extract of Acacia catechu in carbon tetrachloride induced hepatotoxicity. Indian Med Gaz. 2012;12:159-62.

6. Yoganarasimhan SN. Medicinal Plant of India (Karnataka). Bangalore: Indian $\mathrm{J}$ Traditional Knowledge. 2010;9(1):90-5. 
7. Ismail S, Asad M. Immunomodulatory activity of Acacia catechu. Indian $\mathbf{J}$ Physiol Pharmacol. 2009;53(1):25-33.

8. Naik GH, Priyadarsini KI, Satav JG, Banavalikar MM, Sohoni DP, Biyani MK, et al. Comparative antioxidant activity of individual herbal components used in Ayurvedic medicine. Phytochemistry. 2003 May $1 ; 63(1): 97-104$.

9. Davidson JM. Experimental animal wound models. Wounds-a Compendium Clin Res Practice. 2001 Jan 1;13(1):9-23.

10. Guleria S, Tiku AK, Singh G, Vyas D, Bhardwaj A. Antioxidant activity and protective effect against plasmid DNA strand scission of leaf, bark, and heartwood extracts from Acacia catechu. J Food Sci. 2011 Sep;76(7):C959-64.

11. Biswas TK, Mukherjee B. Plant medicines of Indian origin for wound healing activity: a review. Int $\mathrm{J}$ Lower Extremity Wounds. 2003 Mar;2(1):25-39.

12. Monga J, Chauhan CS, Sharma M. Human epithelial carcinoma cytotoxicity and inhibition of DMBA/TPA induced squamous cell carcinoma in Balb/c mice by Acacia catechu heartwood. J Pharmacy Pharmacol. 2011 Nov;63(11):1470-82.

13. Gajera HP, Patel SV, Golakiya BA. Antioxidant properties of some therapeutically active medicinal plants-an overview. JMAPS. 2005;27:91-100.

14. Eloff JN. Which extractant should be used for the screening and isolation of antimicrobial components from plants?. J Ethnopharmacol. 1998 Feb 1;60(1):18.

15. Noorani AA, Mulla K, Patil SD. Hepatoprotective effect of Cocculus hirsutus linn. against ethanolinduced liver damage in albino wistar rats. Pharmacophore. 2010;1(2):82-9.

16. Zhong Y, Chiou YS, Pan MH, Shahidi F. Antiinflammatory activity of lipophilic epigallocatechin gallate (EGCG) derivatives in LPS-stimulated murine macrophages. Food Chemistry. 2012 Sep 15;134(2):742-8.

17. Sulaiman CT, Gopalakrishnan VK, Balachandran I. Spectrophotometric determination of antioxidant potential of selected Acacia species. Medicinal PlantsInt J Phytomed Related Industries. 2011;3(4):289-92.

18. Yimam M, Brownell L, Hodges M, Jia Q. Analgesic effects of a standardized bioflavonoid composition from Scutellaria baicalensis and Acacia catechu. J Dietary Supplements. 2012 Aug 14;9(3):155-65.
19. Arjmandi BH, Ormsbee LT, Elam ML, Campbell SC, Rahnama N, Payton ME, et al. A combination of Scutellaria baicalensis and Acacia catechu extracts for short-term symptomatic relief of joint discomfort associated with osteoarthritis of the knee. J Medicinal Food. 2014 Jun 1;17(6):707-13.

20. Li XC, Liu C, Yang LX, Chen RY. Phenolic compounds from the aqueous extract of Acacia catechu. J Asian Natural Products Research. 2011 Sep 1;13(9):826-30.

21. Hazra B, Sarkar R, Ghate NB, Chaudhuri D, Mandal N. Study of the protective effects of Katha (heartwood extract of Acacia catechu) in liver damage induced by iron overload. J Environmental Pathol Toxicol Oncol. 2013;32(3)

22. Negi BS, Dave BP. In Vitro antimicrobial activity of Acacia catechu and its phytochemical analysis. Indian J Microbiol. 2010 Oct 1;50(4):369-74.

23. Patel JD, Kumar V, Bhatt SA. Antimicrobial screening and phytochemical analysis of the resin part of Acacia catechu. Pharmaceutical Biol. 2009 Jan 1;47(1):34-7.

24. Patil S, Jolly CI, Narayanan S. Free radical scavenging activity of Acacia catechu and Rotula aquatica: implications in cancer therapy. Indian Drugs. 2003;40(6):328-32.

25. Ray D, Sharatchandra KH, Thokchom IS. Antipyretic, antidiarrhoeal, hypoglycaemic and hepatoprotective activities of ethyl acetate extract of Acacia catechu Willd. in albino rats. Indian J Pharmacol. 2006 Nov $1 ; 38(6): 408-13$.

26. Shen D, Wu Q, Wang M, Yang Y, Lavoie EJ, Simon JE. Determination of the predominant catechins in Acacia catechu by liquid chromatography/electrospray ionization- mass spectrometry. J Agricultural Food Chem. 2006 May 3;54(9):3219-24.

27. Sulaiman CT, Balachandran I. Total phenolics and total flavonoids in selected Indian medicinal plants. Indian J Pharmaceutical Sci. 2012 May;74(3):258-60.

Cite this article as: Tangeti $S$, Gabbita P, Ponnaluri RP, Kolasani BP. Comparative study of wound healing effect of topical Acacia catechu extract and silver sulfadiazine on excisional wound model in guinea pigs. Int J Basic Clin Pharmacol 2018;7:234752. 